\title{
Estimating absorption coefficients of colored dissolved organic matter (CDOM) using a semi-analytical algorithm for southern Beaufort Sea waters: application to deriving concentrations of dissolved organic carbon from space
}

\author{
A. Matsuoka ${ }^{1,2}$, S. B. Hooker ${ }^{3}$, A. Bricaud ${ }^{1}$, B. Gentili ${ }^{1}$, and M. Babin ${ }^{1,2}$ \\ ${ }^{1}$ Laboratoire d'Océanographie de Villefranche, Université Pierre et Marie Curie (Paris 6)/ Centre National de la Recherche \\ Scientifique (CNRS), UMR7093, B.P. 08, Port de la Darse, Villefranche-sur-Mer Cedex, 06230, France \\ ${ }^{2}$ Takuvik Joint International Laboratory, Université Laval (Canada) - CNRS (France), Département de Biologie \\ and Québec-Océan, Université Laval, Pavillon Alexandre-Vachon 1045, avenue de la Médecine, Local 2078, G1V 0A6, \\ Canada \\ ${ }^{3}$ National Aeronautics and Space Administration (NASA)/ Goddard Space Flight Center (GSFC), Code 616.2, Bldg. 28 \\ Rm. W120D, Greenbelt, MD 20771, USA
}

Correspondence to: A. Matsuoka (atsushi.matsuoka@takuvik.ulaval.ca)

Received: 4 September 2012 - Published in Biogeosciences Discuss.: 9 October 2012

Revised: 11 January 2013 - Accepted: 14 January 2013 - Published: 8 February 2013

\begin{abstract}
A series of papers have suggested that freshwater discharge, including a large amount of dissolved organic matter (DOM), has increased since the middle of the 20th century. In this study, a semi-analytical algorithm for estimating light absorption coefficients of the colored fraction of DOM (CDOM) was developed for southern Beaufort Sea waters using remote sensing reflectance at six wavelengths in the visible spectral domain corresponding to MODIS ocean color sensor. This algorithm allows the separation of colored detrital matter (CDM) into CDOM and non-algal particles (NAP) through the determination of NAP absorption using an empirical relationship between NAP absorption and particle backscattering coefficients. Evaluation using independent datasets, which were not used for developing the algorithm, showed that CDOM absorption can be estimated accurately to within an uncertainty of $35 \%$ and $50 \%$ for oceanic and coastal waters, respectively. A previous paper (Matsuoka et al., 2012) showed that dissolved organic carbon (DOC) concentrations were tightly correlated with CDOM absorption in our study area $\left(r^{2}=0.97\right)$. By combining the CDOM absorption algorithm together with the DOC versus CDOM relationship, it is now possible to estimate DOC concentrations in the near-surface layer of the southern Beaufort Sea using satellite ocean color data. DOC concentrations in the sur-
\end{abstract}

face waters were estimated using MODIS ocean color data, and the estimates showed reasonable values compared to in situ measurements. We propose a routine and near real-time method for deriving DOC concentrations from space, which may open the way to an estimate of DOC budgets for Arctic coastal waters.

\section{Introduction}

The colored fraction of dissolved organic matter (CDOM) plays various roles in physical and biogeochemical processes (e.g., Carder et al., 1989; Miller and Moran, 1997; Nelson et al., 1998; Miller et al., 2002; Matsuoka et al., 2012). The contribution of CDOM light absorption to the total non-water absorption for Arctic waters is significantly higher than at lower latitudes (Bélanger et al., 2006; Matsuoka et al., 2007, 2009, 2011), playing a role as a heat absorption mechanism and thereby contributing to sea ice reduction (Hill, 2008; Matsuoka et al., 2011). Recent findings suggest that, on land, global warming likely induces thawing of the permafrost containing a significant amount of dissolved organic carbon (DOC) (Freeman et al., 2001; Camill, 2005; Frey and Smith, 2005). Because the freshwater discharge into Arctic rivers 
has increased since the middle of the 20th century (Peterson et al., 2002; McClelland et al., 2006), a large amount of CDOM, whose absorption is often highly correlated with DOC concentrations at the mouth of a river (e.g., Mannino et al., 2008; Fichot and Benner, 2011; Matsuoka et al., 2012), is expected to be delivered into the Arctic Ocean by the river discharge relative to its autotrophic sources. During ice-free seasons, this material covers the surface ocean and significantly reduces penetration of ultraviolet irradiation that influences marine organisms such as phytoplankton and bacteria (Judd et al., 2007; Leu et al., 2007; Bonilla et al., 2009; Hessen et al., 2012). In the context of the expansion of the hole in ozone layer at high northern latitudes (e.g., Wirth and Renger, 1996; Andersen and Knudsen, 2002), variability in CDOM absorption can impact the physiological status or acclimation/adaptation of marine organisms. Quantitative estimation and monitoring of CDOM in Arctic coastal environments are therefore urgently needed to better understand the modification in biogeochemical processes resulting from ongoing global warming.

Because of the similarity in absorption spectra between CDOM and non-algal particles (NAP), the two are often combined together as a single geophysical value, CDM (=CDOM + NAP) absorption (e.g., Garver and Siegel, 1997; Lee et al., 2002; Maritorena et al., 2002). Although basinscale observations of CDM absorption using ocean color have provided insights into its linkages with phytoplankton biomass or the influence of photobleaching (Siegel et al., 2002; Bricaud et al., 2012), two important issues remain unsolved. First, these studies did not take into account variability in CDM absorption in coastal areas where large amounts of suspended sediments and dissolved organic matter are delivered by rivers. Because of the optical complexity of coastal waters, retrieved inherent optical properties (IOPs) tend to be more variable and thus uncertain in coastal areas compared to those in open ocean areas (e.g., IOCCG, 2006; Kostadinov et al., 2007). In contrast to open oceanic waters in which CDOM absorption and DOC concentration are generally not correlated (Siegel et al., 2002; Nelson and Siegel, 2002), the tight correlation between these two variables for coastal waters can be used for deriving DOC concentrations from space when CDOM absorption is estimated accurately using ocean color data.

The second issue related to the use of CDM absorption is that it is difficult to understand the different dynamics of CDOM and NAP separately. For example, particles sink rather quickly, at a vertical speed ranging from a few meters to several hundred meters per day (Fischer and Karakas, 2009), while CDOM can be transported by an ocean current over long distances $(>1000 \mathrm{~km})$ in a few months (Matsuoka et al., 2011, 2012). Consequently, partitioning CDM into CDOM and NAP using a semi-analytical algorithm is required, but it is difficult due to their similar spectral shapes (IOCCG, 2006). While recent studies developed local and empirical algorithms for estimating CDOM absorp- tion (D'Sa, 2008; Mannino et al., 2008), the products derived using those algorithms can be significantly affected by spatial and seasonal variations in the empirical relationships. A semi-analytical algorithm is thus required to account for these variations. Such an algorithm was recently developed for the Mississippi and Atchafalaya regions (Zhu et al., 2011).

The objective of this study is to develop a semi-analytical algorithm for estimating CDOM absorption for Arctic waters. The application for deriving DOC concentrations using ocean color data is proposed at the end of this paper.

\section{Materials and methods}

\subsection{Datasets for developing the CDOM absorption algorithm}

The IOPs datasets used for developing our semi-analytical CDOM absorption algorithm are documented in Matsuoka et al. (2007, 2011). Briefly, sampling was conducted in the western Arctic Ocean in the area from approximately latitudes $65^{\circ}$ to $77^{\circ} \mathrm{N}$ and longitudes $145^{\circ}$ to $180^{\circ} \mathrm{W}$ (Fig. 1). Data were collected during three cruises ranging from spring to autumn (from May to October): the Western Arctic ShelfBasin Interactions (SBI) spring and summer cruises in 2002 aboard the USCGC Healy (referred to as SBI spr: 5 May to 15 June 2002, and SBI sum: 16 July to 26 August 2002), and the autumn cruise in 2004 of the "Studies on Arctic Ocean circulation linked to Arctic climate system" conducted onboard by the Japanese R/V Mirai (referred to as MR aut: 1 September to 13 October 2004). Discrete water samples were collected using Niskin bottles, except at the surface where a polyethylene container was used during the MR aut cruise. In total, 110, 119, and 179 water samples were collected at 30 (SBI spr), 29 (SBI sum), and 51 (MR aut) stations for pigment and absorption analyses within the euphotic zone (i.e., between the surface and the euphotic depth, $z_{\mathrm{eu}}$, where $1 \%$ of the surface irradiance subsists). Absorption coefficients of particles $\left(a_{\mathrm{p}}(\lambda), \mathrm{m}^{-1}\right)$ retained on GF/F filters were determined from 350 to $750 \mathrm{~nm}$ using a MPS-2400 spectrophotometer (Shimazu Corp.). Phytoplankton pigments retained on the filters were extracted using methanol (Kishino et al., 1985), absorption coefficients of $\operatorname{NAP}\left(a_{\mathrm{NAP}}(\lambda), \mathrm{m}^{-1}\right)$ were measured on the bleached filter, and phytoplankton absorption coefficients $\left(a_{\varphi}(\lambda), \mathrm{m}^{-1}\right)$ were obtained by subtracting $a_{\mathrm{NAP}}(\lambda)$ from $a_{\mathrm{p}}(\lambda)$. For the absorption measurements of CDOM, water samples were filtered using $0.22 \mu \mathrm{m}$ Millipore membranes immediately after water sampling and then poured into a $0.1 \mathrm{~m}$ quartz cell. Absorption coefficients of CDOM were determined from 280 to $700 \mathrm{~nm}$ using a MPS2400 spectrophotometer (Shimazu Corp.). All absorption measurements were made following the NASA ocean color protocols (Mitchell et al., 2003). 


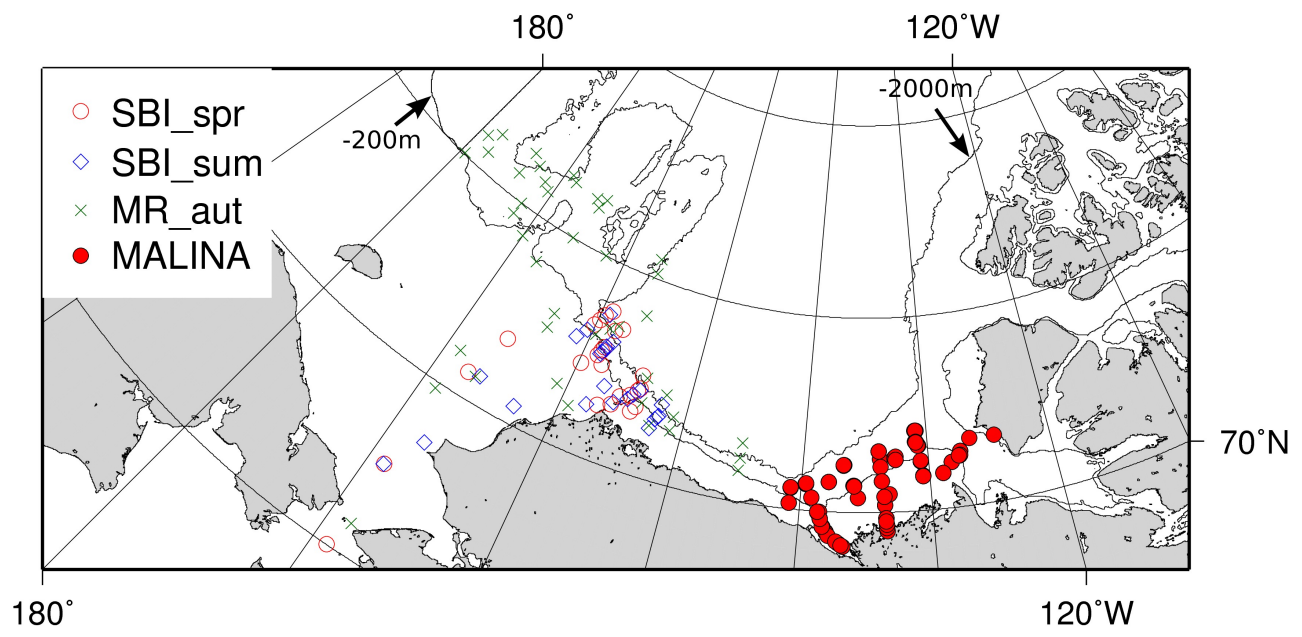

Fig. 1. Locations of sampling stations for the SBI spr (red open circles), SBI sum (blue diamonds), MR aut (green crosses), and MALINA (red closed circles) in the western Arctic Ocean. Note that the SBI spr, SBI sum, and MR aut datasets were used to develop our CDOM absorption algorithm. The MALINA dataset was used to evaluate the performance of the algorithm.

In this study, chl $a$ concentrations were determined fluorometrically with $90 \%$ acetone (Holm-Hansen et al., 1965) for SBI spr and SBI sum and with dimethylformamide (DMF) (Holm-Hansen et al., 1965; Suzuki and Ishimaru, 1990) for MR aut using a 10AU field fluorometer (Turner Designs). Suzuki and Ishimaru (1990) showed that chl $a$ concentration obtained using DMF is not significantly different from that determined using $90 \%$ acetone.

\subsection{In situ datasets}

\subsubsection{CDOM absorption and DOC determination}

CDOM absorption datasets for evaluating our CDOM algorithm are documented in Matsuoka et al. (2012). Briefly, measurements were performed in the southern Beaufort Sea during the France-Canada-USA joint Arctic campaign, MALINA, in the area from approximately latitudes $69^{\circ}$ to $72^{\circ} \mathrm{N}$ and longitudes $125^{\circ}$ to $145^{\circ} \mathrm{W}$ (Fig. 1). Sampling was conducted from 30 July to 26 August 2009 aboard the Icebreaker CCGS Amundsen, and 37 stations were visited. A barge and/or zodiac were also deployed (32 stations out of 37) during the same time periods of the CTD deployment to obtain surface water samples (see Fig. A1 of Matsuoka et al., 2012). The absorption of CDOM in the sample filtrate was measured over the spectral range $200-735 \mathrm{~nm}$ using an UltraPath liquid waveguide system (World Precision Instruments, Inc.). A $2 \mathrm{~m}$ optical pathlength was used for almost all waters, except for coastal waters in the Mackenzie River mouth where a $0.1 \mathrm{~m}$ optical pathlength was used. The detailed methodology is described in Matsuoka et al. (2012).

Dissolved organic carbon (DOC) was measured using the high-temperature combustion method and a TOC-V analyzer (Shimadzu) (Benner and Strom, 1993). Water samples using Whatman GF/F filters were stored frozen until analysis in laboratory. In total, 256 samples were collected for DOC analyses at 29 stations (DOC measurements were made by R. Benner).

\subsubsection{Calculation of remote sensing reflectance}

A detailed methodology for obtaining in-water upwelled radiance $\left(L_{\mathrm{u}}\right)$ and downward irradiance $\left(E_{\mathrm{d}}\right)$ is documented in Hooker et al. (2013). Briefly, a Compact-Optical Profiling System (C-OPS) (Morrow et al., 2010) was deployed at 36 stations during the MALINA cruise. We obtained above- and in-water light measurements at 18 channels (i.e., 320, 340, $380,395,412$, 443, 465, 490, 510, 532, 555, 560, 625, 665, $670,683,710$, and $780 \mathrm{~nm})$. The above-water global solar irradiance $\left(E_{\mathrm{S}}\right)$ measurements were used to correct the $E_{\mathrm{d}}$ and $L_{\mathrm{u}}$ data for change in the incident light field. Additional corrections included dark currents, pressure tares, aperture offsets (distance to pressure transducer), tilt filtering ( $5^{\circ}$ or less), and self-shading (Hooker et al., 2013). Subsurface $L_{\mathrm{u}}$ at null depth (i.e., $L_{\mathrm{u}}\left(0^{-}, \lambda\right)$ ) were obtained from the slope and intercept given by the least-squares linear regression of the log-transformed light parameter versus $z$. The top and the bottom of the extrapolation interval were, on average, $0.12 \mathrm{~m}$ and $1.96 \mathrm{~m}$, respectively. The principal data product used here is the remote sensing reflectance, $R_{\mathrm{rS}}(\lambda)=0.54 L_{\mathrm{u}}\left(0^{-}\right.$, $\lambda) / E_{\mathrm{s}}(\lambda)$, where $\lambda$ indicates wavelength. In this study, $R_{\mathrm{rs}}(\lambda)$ at six wavelengths (i.e., 412, 443, 490, 532, 555, and $670 \mathrm{~nm}$ corresponding approximately to MODIS bands) were used.

\subsection{Semi-analytical algorithms for deriving CDOM absorption and DOC concentration}

In this study, we developed a semi-analytical algorithm for estimating CDOM absorption at $443 \mathrm{~nm}$ for Arctic waters. The overview of this algorithm is schematically shown in 


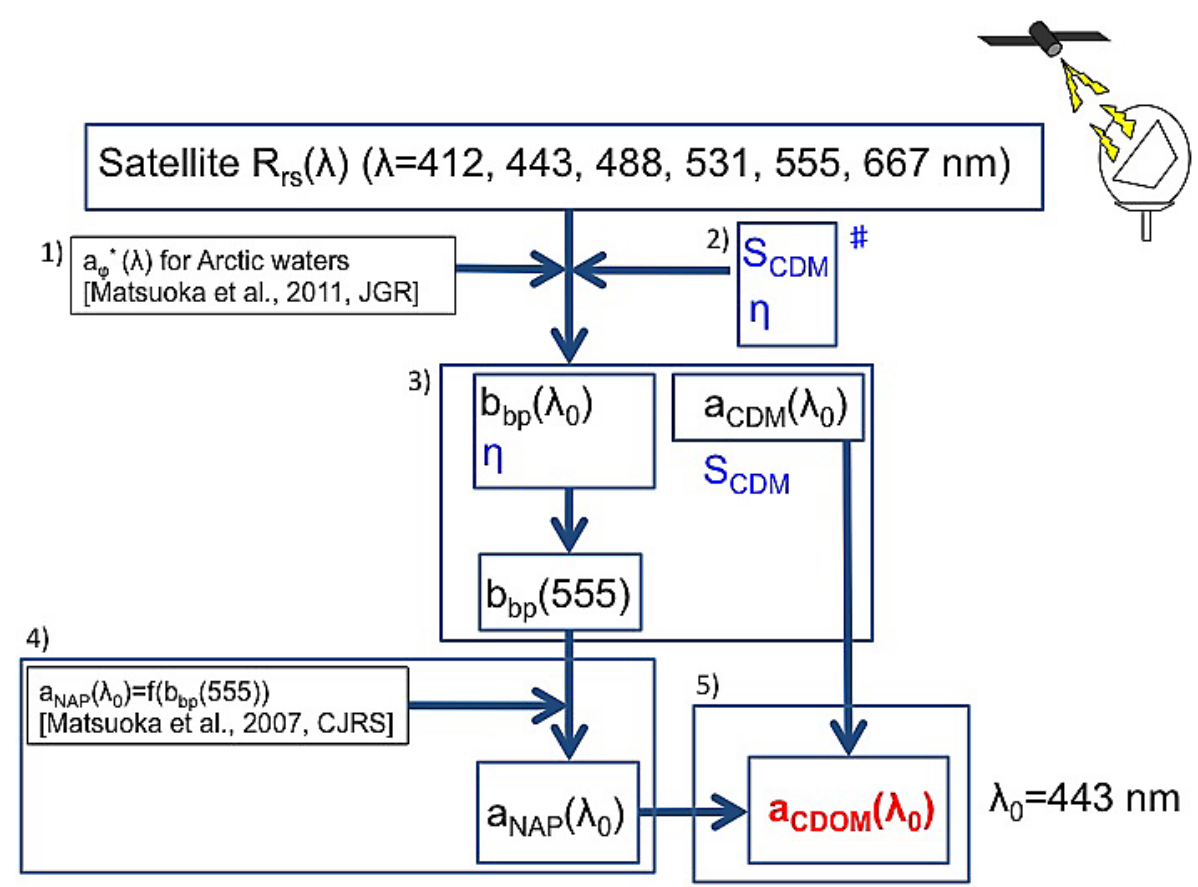

Fig. 2. A flow-chart of our semi-analytical algorithm for estimating CDOM absorption. A "\#” represents parameters which can be set either to be constant or as a function of $R_{\mathrm{rs}}(\lambda)$, depending on water class. These classes are determined using cluster analysis (Sect. 3.2). The coefficients used in the relationship $a_{\varphi}^{*}(\lambda)=A(\lambda)(\mathrm{chl})^{-B(\lambda)}$ and the empirical relationship between $a_{\mathrm{NAP}}(443)$ and $b_{\mathrm{bp}}(555)$ used in our CDOM algorithm are summarized in Table A1.

Fig. 2 (see also Table A1). Basically, we used a mathematical iteration method for minimizing the difference between measured $R_{\mathrm{rs}}(\lambda)$ and $R_{\mathrm{rs}}(\lambda)$ calculated using absorption and backscattering coefficients, as in the Garver-SiegelMaritorena (GSM) model (Garver and Siegel, 1997; Maritorena et al., 2002), but with the following 5 modifications: (1) chl $a$-specific absorption coefficients of phytoplankton for Arctic waters (Matsuoka et al., 2011) were used; (2) spectral slopes of CDM absorption, $S_{\mathrm{CDM}}\left(\mathrm{nm}^{-1}\right)$, and of $b_{\mathrm{bp}}(\lambda)$ and $\eta$ (unitless) were set either to be constants or as a function of $R_{\mathrm{rs}}(\lambda)$ (those parameters were determined based on a sensitivity analysis conducted in this study; see section 3.2 for details); (3) $b_{\mathrm{bp}}$ (555) was calculated using $b_{\mathrm{bp}}(443)$ and $\eta$; (4) $a_{\mathrm{NAP}}(443)$ was calculated using the empirical relationship between $a_{\mathrm{NAP}}(443)$ and $b_{\mathrm{bp}}(555)$ obtained for Arctic waters (i.e., $a_{\mathrm{NAP}}(443)=b_{\mathrm{bp}}(555) / 0.2393$; Matsuoka et al., 2007); and (5) $a_{\mathrm{CDOM}}(443)$ was obtained by subtracting $a_{\mathrm{NAP}}(443)$ from $a_{\mathrm{CDM}}(443)$. Finally, DOC concentrations were estimated using an empirical relationship between DOC concentrations and CDOM absorption obtained in the southern Beaufort Sea (i.e., DOC $(\mu \mathrm{M})=55+357 \times a_{\mathrm{CDOM}}(443)$, Matsuoka et al., 2012).

\subsection{Ocean color data}

Three-weeks composite images of $R_{\mathrm{rs}}(\lambda)$ at 412, 443, 488, 531, 551, and $670 \mathrm{~nm}$ in August 2009 were generated us- ing Aqua/MODIS ocean color data. After Level 1A data were downloaded from the ocean color website (http:// oceancolor.gsfc.nasa.gov/cgi/browse.pl?sen=am), geometric correction was made using the SeaWiFS Data Analysis System (SEADAS) software. Because the use of MODIS nearinfrared bands (748 and $869 \mathrm{~nm}$ ) for atmospheric correction (i.e., NASA standard atmospheric correction: Gordon and Wang, 1994; Gordon, 1997) often yielded pixels having negative values, especially in $R_{\mathrm{rs}}(412)$ in coastal areas of the southern Beaufort Sea (which were flagged), a new method that can be applied to turbid ocean waters, proposed by Wang and Shi (2007), was used to obtain $R_{\mathrm{rs}}(\lambda)$ images in this study. This algorithm basically operates in the same way as that of Gordon and Wang (1994), but the two NIR bands (i.e., 748 and $869 \mathrm{~nm}$ ) are replaced by two SWIR bands (i.e., 1240 and $2130 \mathrm{~nm}$ ) for atmospheric correction.

\section{Results and discussion}

\subsection{Variability in $R_{\mathrm{rs}}(\lambda)$}

Because we used $R_{\mathrm{rS}}(\lambda)$ spectra to estimate CDOM absorption using our semi-analytical algorithm (section 3.2), those spectra are presented first. There were a variety of $R_{\mathrm{rs}}(\lambda)$ spectral shapes observed in this study from coastal to open ocean waters (Fig. 3a): $R_{\mathrm{rs}}(\lambda)$ spectra in coastal waters had a peak at $555 \mathrm{~nm}$ or longer wavelengths, while those in 

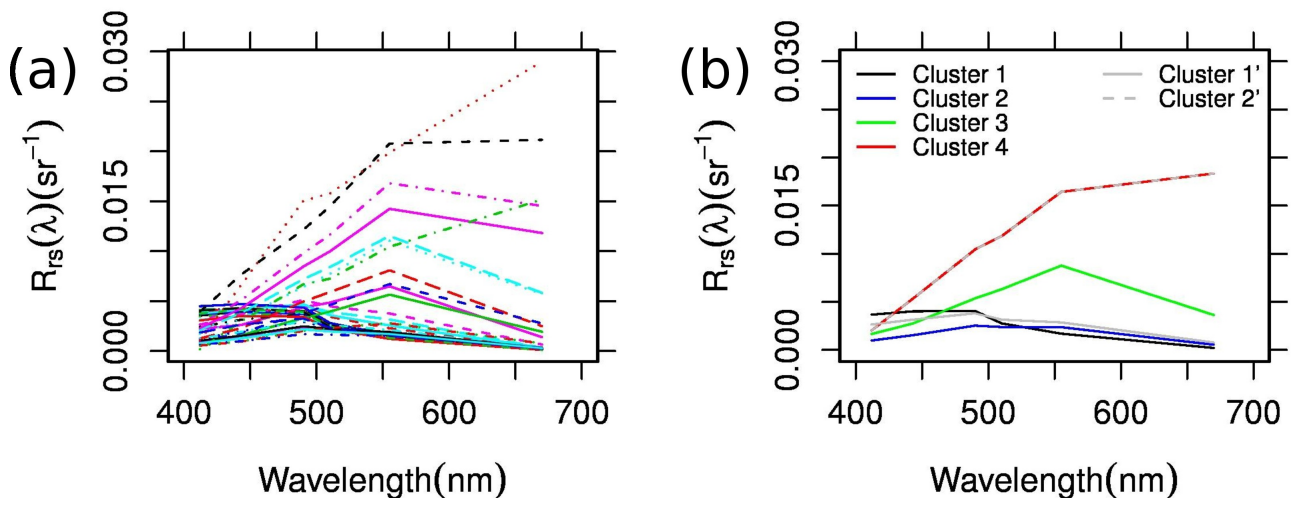

Fig. 3. $R_{\mathrm{rs}}(\lambda)$ spectra observed during the MALINA cruise: (a) all $R_{\mathrm{rs}}(\lambda)$ spectra, and (b) classified $R_{\mathrm{rs}}(\lambda)$ spectra using k-means cluster analysis.

offshore waters showed a peak at wavelengths ranging from 412 to $490 \mathrm{~nm}$. These spectral shapes look similar to those observed everywhere at lower latitudes (see Werdell and Bailey, 2005, and references therein), but the IOPs for Arctic waters are significantly different from those for lower latitudes (Matsuoka et al., 2007, 2011). A parameterization of IOPs specific to Arctic waters is therefore required to adequately derive geophysical values from $R_{\mathrm{rs}}(\lambda)$ spectra (Matsuoka et al., 2011). In this study, Arctic-specific parameters are used for estimating CDOM absorption (Sect. 3.2).

To generalize $R_{\mathrm{rs}}(\lambda)$ spectral shapes, k-means cluster analysis was performed. The best number of classes $(\mathrm{CN})$ was determined based on a minimum value of the CalinskiHarabasz index, which was found to be equal to 4 (Fig. 3b and Table 1). This index is one of the best methods to objectively obtain an optimal number of classes and may be applied to a variety of datasets (Calinski and Harabasz, 1974). Turbidity of waters tended to increase from cluster 1 to 4 , with the clusters roughly corresponding to those observed in the Chukchi Sea, except for cluster 4 (Matsuoka et al., 2007). Cluster 4 was observed especially in the Mackenzie River mouth. Similar clusters were also identified when a CN of 2 was set (gray solid and dashed lines for oceanic and coastal waters, respectively, in Fig. 3b). Therefore, although a CN of 4 was determined from the statistical point of view, it is noted that two clusters (oceanic and coastal) are enough for estimating CDOM absorption using the algorithm developed in this study. Waters can then be classified automatically and systematically before our CDOM absorption algorithm is applied (see Fig. 6 and Sect. 4).

\subsection{Evaluating our algorithm for the retrieval of CDOM absorption}

In situ $a_{\mathrm{CDOM}}(443)$ values for southern Beaufort Sea waters varied widely from offshore to the coast $(0.018<$ $a_{\mathrm{CDOM}}(443)<1.08 \mathrm{~m}^{-1}$; see Fig. 4 of Matsuoka et al., 2012). In our observations, $a_{\mathrm{CDOM}}(443)$ on average ac-
Table 1. Summary of cluster analysis.

\begin{tabular}{lrrrrr}
\hline Number of cluster & 2 & 3 & 4 & 5 & 6 \\
\hline $\begin{array}{l}\text { Calinski-Harabasz } \\
\text { index }\end{array}$ & 113.9 & 97.3 & 79.5 & 151.1 & 181.4 \\
\hline
\end{tabular}

counted for $72 \pm 15 \%$ of total non-water absorption, which is consistent with previous findings in the same study area (Bélanger et al.., 2006; Matsuoka et al., 2007, 2009).

The $a_{\mathrm{CDOM}}(443)$ values estimated using our CDOM absorption algorithm $\left(a_{\mathrm{CDOM}}^{\mathrm{mod}}(443), \mathrm{m}^{-1}\right)$ were evaluated against in situ measurements (Fig. 4). In this study, a sensitivity analysis of the algorithm was performed by varying $\eta$ and $S_{\mathrm{CDM}}$ values (i.e., the step 2 in the Fig. 2; see also Table 2), which are often set as constants (Lee et al., 2002; Maritorena et al., 2002); these can actually be parameterized as functions of $R_{\mathrm{rs}}(\lambda)$ (see Appendix A). Since CDOM absorption values were significantly different between CTD/Niskin and Barge samples (see Fig. A1 of Matsuoka et al., 2012), the performance of the algorithm was evaluated separately for each category (i.e., CTD/Niskin or Barge; CTD/Niskin and Barge correspond to oceanic and coastal waters, respectively). Note that while three empirical algorithms for estimating $a_{\mathrm{CDOM}}$ (443) using SBI spr and SBI sum datasets (MR dataset was not used because of lack of $R_{\mathrm{rs}}(555)$ data) were evaluated, there were almost no correlations between $a_{\mathrm{CDOM}}(443)$ and each $R_{\mathrm{rs}}(\lambda)$ ratio (see Table A2). Thus, these relationships could not be used for estimating $a_{\mathrm{CDOM}}(443)$ in this study.

For oceanic samples, the best performance was obtained when $\eta$ and $S_{\mathrm{CDM}}$ were set to be 1.0 and 0.0185 , respectively (Fig. 4a). Excluding only one outlier (dotted circle), all data points fell within the $\pm 35 \%$ error. The root mean squared error (RMSE) and absolute percent difference (APD) were low, and the corresponding coefficient of determination was high $\left(\mathrm{RMSE}=0.06, \mathrm{APD}=11.1 \%\right.$, and $\left.r^{2}=0.98\right)$. It is important 
Table 2. Comparison of $a_{\mathrm{CDOM}}(443)$ estimates with measured $a_{\mathrm{CDOM}}(443)$ for either oceanic or coastal water samples.

\begin{tabular}{|c|c|c|c|c|c|c|c|c|c|c|c|c|}
\hline \multirow{2}{*}{$\begin{array}{l}\text { Sample } \\
\text { Parameter }\end{array}$} & \multicolumn{6}{|c|}{ Oceanic waters } & \multicolumn{6}{|c|}{ Coastal waters } \\
\hline & $r^{2}$ & Intercept & Slope & RMSE & APD & $N$ & $r^{2}$ & Intercept & Slope & RMSE & APD & $N$ \\
\hline $1-1$ & 0.98 & 0.003 & 0.88 & 0.06 & 11.1 & 29 & 0.65 & -0.0086 & 1.51 & 0.18 & 29.3 & 35 \\
\hline $1-2$ & 0.81 & 0.022 & 0.62 & 0.10 & 16.4 & 29 & 0.67 & 0.002 & 0.84 & 0.17 & 24.6 & 35 \\
\hline $2-1$ & 0.87 & 0.017 & 0.62 & 0.09 & 11.4 & 29 & 0.84 & -0.025 & 0.93 & 0.15 & 20.3 & 35 \\
\hline $2-2$ & 0.73 & 0.025 & 0.67 & 0.12 & 24.7 & 29 & 0.72 & -0.035 & 1.08 & 0.16 & 23.9 & 35 \\
\hline
\end{tabular}

$1-1: \eta=1.0$ and $S_{\mathrm{CDM}}=0.0185$

$1-2: \eta=1.0$ and $S_{\mathrm{CDM}}=f\left(R_{\mathrm{rs}}(\lambda)\right)$.

$2-1: \eta=f\left(R_{\mathrm{rS}}(\lambda)\right)$ and $S_{\mathrm{CDM}}=0.0185$.

2-2: $\eta=f\left(R_{\mathrm{rs}}(\lambda)\right)$ and $S_{\mathrm{CDM}}=f\left(R_{\mathrm{rS}}(\lambda)\right)$.

RMSE: root mean square error.

APD : absolute percent difference.
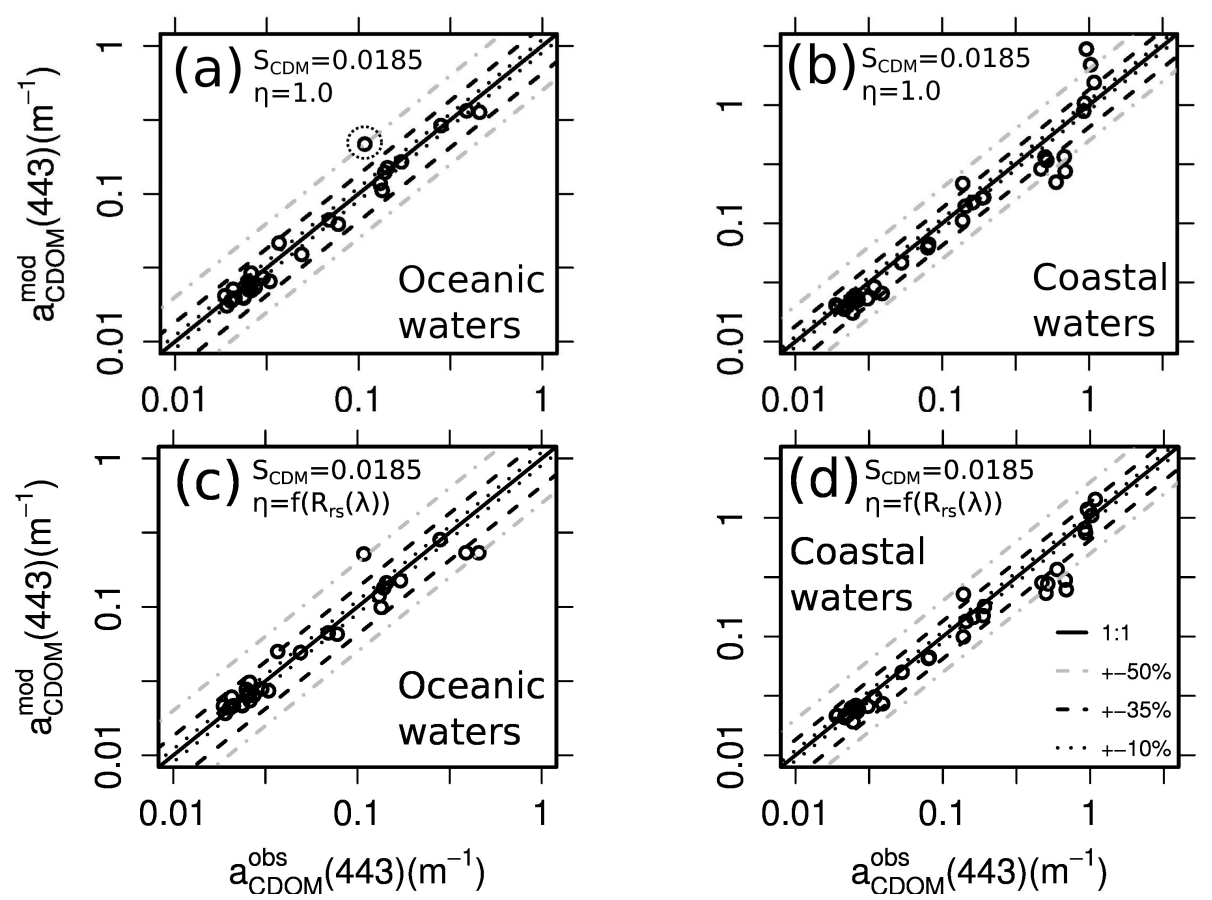

Fig. 4. A comparison of estimated CDOM absorption $\left(a_{\mathrm{CDOM}}^{\mathrm{mod}}(443)\right)$ with in situ measurements $\left(a_{\mathrm{CDOM}}^{\mathrm{obs}}{ }^{(443))}\right)$. Upper panels: $a_{\mathrm{CDOM}}^{\mathrm{mod}}(443)$ using a fixed $\eta=1.0$ and $S_{\mathrm{CDM}}=0.0185$ (case 1-1 in Table 2) for (a) oceanic and (b) coastal waters. Lower panels: $a_{\mathrm{CDOM}}{ }^{(443)}$ using $\eta$ as a function of $R_{\mathrm{rs}}(\lambda)$ and a constant $S_{\mathrm{CDM}}=0.0185$ (case 2-1 in Table 2) for (c) oceanic and (d) coastal waters.

to note that this evaluation was conducted using independent datasets (i.e., MALINA datasets) that were not used for developing the algorithm (i.e., SBI spr, SBI sum, and MR aut datasets were used for this development). While parameterization of IOPs was made for typical oceanic waters (not directly influenced by river discharge) of the Arctic Ocean (Matsuoka et al., 2011), the evaluation results suggest this parameterization can also be applied for Arctic coastal waters directly influenced by the discharge of the Mackenzie River. This idea is partly supported by the fact that phytoplankton absorption properties, which were used for tuning the algorithm (see step 1 in Fig. 2), are similar between oceanic and coastal waters for the same season in the Arctic Ocean (Matsuoka et al., 2009).

A slope slightly lower than 1 was obtained using our algorithm (slope $=0.88$; see Table 2 and Fig. $4 a$ ). This bias should be examined in a future study by collecting more samples over a wide range of CDOM content. Nonetheless, this semianalytical algorithm provides estimates of CDOM absorption within a $\pm 35 \%$ accuracy for oceanic waters.

For coastal samples, on the other hand, the CDOM algorithm with the fixed $\eta$ and $S_{\mathrm{CDM}}$ values did not perform well, especially for high CDOM absorption values (RMSE $=0.18, \mathrm{APD}=29.3 \%$, and $r^{2}=0.65$; see Fig. $4 \mathrm{~b}$ and Table 2). The slope of $a_{\mathrm{CDOM}}^{\mathrm{mod}}(443)$ versus $a_{\mathrm{CDOM}}^{\mathrm{obs}}(443)$ 

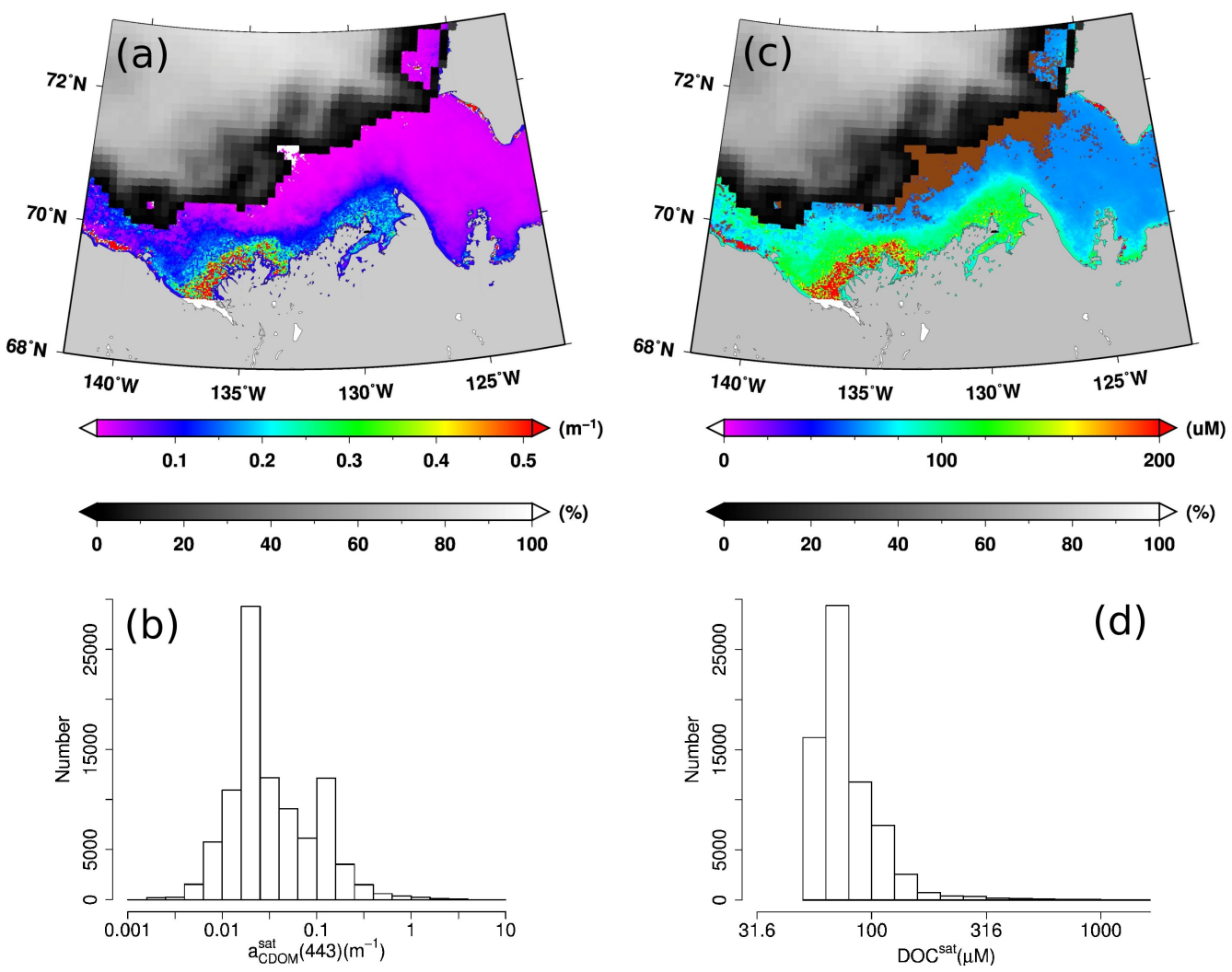

Fig. 5. (a) A composite image of CDOM absorption, $a_{\mathrm{CDOM}}^{\text {sat }}(443)$ for August 2009 using three weeks of MODIS $R_{\mathrm{rs}}(\lambda)$ data, with sea ice concentration shown in gray. (b) Histogram of $a_{\mathrm{CDOM}}^{\text {sat }}$ (443) values shown in (a). (c) An image of DOC concentration, DOC ${ }^{\text {sat }}$ for August 2009 using our DOC vs. $a_{\mathrm{CDOM}}(443)$ algorithm applied to the image shown in (a). DOC ${ }^{\text {sat }}$ concentrations lower than $61 \mu \mathrm{M}$ (outside the regression of DOC vs. $a_{\mathrm{CDOM}}(443)$ relationship) are masked as brown. (d) Histogram of DOC ${ }^{\text {sat }}$ values shown in (c).

was high (i.e., 1.51). The best performance was obtained for coastal samples when using fixed $S_{\mathrm{CDM}}$ and varying $\eta$ as a function of $R_{\mathrm{rs}}(\lambda)$ (Fig. 4d; see also Appendix A). Using this algorithm, we were able to estimate CDOM absorption for coastal waters within $\pm 50 \%$ accuracy except for a few data points. This suggests that unlike $S_{\mathrm{CDM}}$, the choice of the $\eta$ value impacts the performance of the CDOM algorithm for coastal waters (Fig. 4c). This result is consistent with the fact that optical properties in a thin layer at the top of the surface waters were characterized by high backscattering of various types of particles, especially in the Mackenzie River mouth (Hooker et al., 2013; Doxaran et al., 2012), altering the $\eta$ value. Due to scattering of particles as well as high CDOM absorption, the light penetration depth was very shallow in the Mackenzie River mouth $(1.38 \pm 1.82 \mathrm{~m})$, but was deep in offshore areas $(16.65 \pm 9.84 \mathrm{~m})$. Thus, $\eta$ and $S_{\mathrm{CDM}}$ parameters need to be set separately for oceanic and coastal waters. $S_{\mathrm{CDM}}$ varies widely in global ocean basins (Bricaud et al., 2012), while this value tends to be constant in coastal areas (Babin et al., 2003; Magnuson et al., 2004). Our result may imply that waters in the southern Beaufort Sea are strongly influenced by one given end-member, the Mackenzie River discharge, making $S_{\mathrm{CDM}}$ stable (Matsuoka et al., 2012). The variability in this parameter needs to be examined further for Arctic waters.

\subsection{Deriving DOC concentration using ocean color}

In this section, we applied our CDOM absorption algorithm for Aqua/MODIS ocean color images. The three-week composite images in August 2009 were generated in order to correspond to the period of the MALINA cruise.

Overall, $a_{\mathrm{CDOM}}^{\text {sat }}(443)$ values were high in the western channel compared to those in the eastern channel of the Mackenzie delta. This result is consistent with our field observations (Fig. 5a; see Fig. 6 in Matsuoka et al., 2012). Geometric mean and geometric standard deviation values of $a_{\mathrm{CDOM}}^{\text {sat }}(443)$ (0.034 and $2.776 \mathrm{~m}^{-1}$, respectively) were of the same order of magnitude compared to our observations for the MALINA cruise $\left(0.055\right.$ and $2.265 \mathrm{~m}^{-1}$, respectively) (Fig. 5b; Matsuoka et al., 2012).

In the Mackenzie River mouth, Matsuoka et al. (2012) observed that DOC concentrations (ranging $55 \mu \mathrm{M}<\mathrm{DOC}<500 \mu \mathrm{M})$ in the surface layer were tightly correlated with $a_{\mathrm{CDOM}}(443)$ (ranging $0.018 \mathrm{~m}^{-1}$ $\left.<a_{\mathrm{CDOM}}(443)<1.08 \mathrm{~m}^{-1}\right) \quad\left(r^{2}=0.97 ; \quad p<0.0001\right)$. 


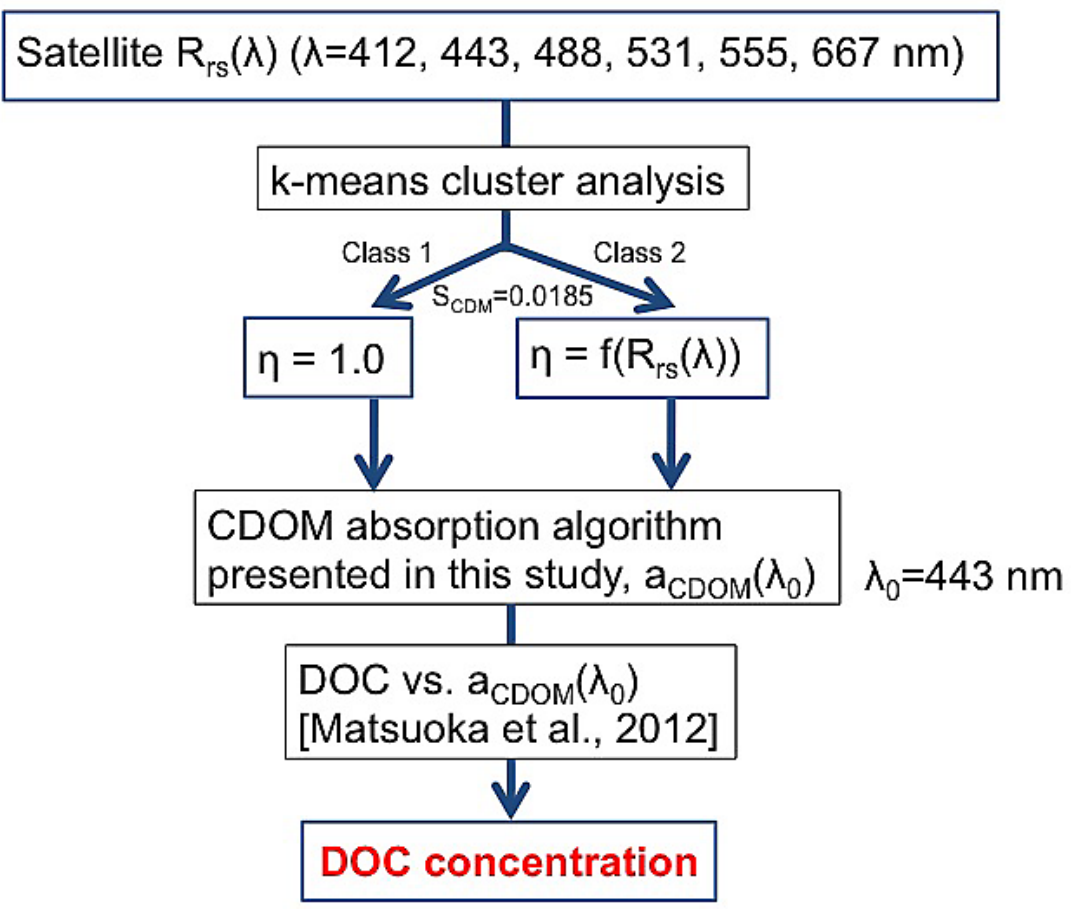

Fig. 6. A flow chart for deriving DOC concentrations for Arctic waters using satellite ocean color data.

Combining the CDOM absorption algorithm developed in this study with the DOC versus CDOM relationship published by Matsuoka et al.(2012), it is now possible to derive DOC concentrations in the surface layer of the southern Beaufort Sea using satellite ocean color data. We applied this method to $a_{\mathrm{CDOM}}(443)$ images for deriving surface DOC concentrations. Note that the DOC versus $a_{\mathrm{CDOM}}(443)$ relationship we use is valid for waters from the Mackenzie River mouth to offshore waters near the ice edge area.

Consistent with $a_{\mathrm{CDOM}}^{\text {sat }}(443)$ values, high DOC concentrations $(>100 \mu \mathrm{M})$ were widely distributed in the Mackenzie shelf area (Fig. $5 \mathrm{c}-\mathrm{d}$ ). The geometric mean of DOC ${ }^{\text {sat }}$ was $79 \mu \mathrm{M}$, which was similar to that observed for the MALINA cruise (Matsuoka et al., 2012). This result suggests that our estimation of DOC concentrations performs reasonably well, highlighting the potential utility of the algorithm for deriving DOC concentrations in the surface layer and further estimating the DOC budget for Arctic coastal waters.

\section{Conclusions}

In this study, we developed a semi-analytical algorithm for estimating CDOM absorption for Arctic waters. Comparison with in situ measurements showed that $a_{\mathrm{CDOM}}(443)$ can be estimated accurately to within an uncertainty of $35 \%$ and $50 \%$ for oceanic and coastal waters of the Arctic Ocean, respectively. While we acknowledge that the estimation of
$a_{\mathrm{CDOM}}(443)$ in highly turbid waters is still a challenging task (Zhu et al., 2011; this study), to our knowledge, this is the first semi-analytical algorithm for estimating CDOM absorption for Arctic waters. This approach allows a partitioning of CDM (i.e., CDOM plus NAP) into CDOM and NAP absorption contributions, thereby promoting an understanding of the dynamics for each component.

As a result of combining the CDOM absorption algorithm together with the DOC versus CDOM relationship, we propose a routine and near real-time method for deriving DOC concentrations for Arctic coastal waters using satellite ocean color data (Fig. 6). First, satellite $R_{\mathrm{rs}}(\lambda)$ spectra are categorized into two classes according to their spectral shapes. This can be made using supervised classification referring to clusters $1^{\prime}$ and $2^{\prime}$ obtained in this study (Fig. 3b). Second, parameterization of $\eta$ and $S_{\mathrm{CDM}}$ is set to be either constant or as a function of $R_{\mathrm{rS}}(\lambda)$ depending on a $R_{\mathrm{rS}}(\lambda)$ spectral class. Third, our CDOM absorption algorithm is applied. Finally, DOC concentrations are estimated using a relationship between DOC and $a_{\mathrm{CDOM}}(443)$ derived from in situ measurements. Although this kind of method is potentially useful for estimating and monitoring change in DOC budgets for Arctic coastal waters as a result of ongoing global warming, the DOC versus $a_{\text {CDOM }}(443)$ relationship was obtained empirically during summer in the southern Beaufort Sea and might vary seasonally; a peak DOC flux occurs during ice melt in the early spring, significantly contributing to the DOC budget (Holmes et al., 2008). Further field observations are thus required to address this issue. 
Table A1. Summary of the relationships used for developing our CDOM algorithm for Arctic waters.

\begin{tabular}{llcc}
\hline Equation & Function & $\begin{array}{c}\text { Block number } \\
\text { in Fig. 2 }\end{array}$ & Reference \\
\hline$a_{\varphi}^{*}(\lambda)$ & $A_{\varphi}(\lambda)(\mathrm{chl})^{-B \varphi(\lambda)}$ & 1 & Matsuoka et al. (2011) \\
& $A_{\varphi}(\lambda)=(0.0273,0.0298,0.0192,0.0138,0.006,0.0127)$ & & \\
& $B_{\varphi}(\lambda)=(0.3443,0.3480,0.3604,0.3487,0.3428,0.2867)$ & & \\
& $\lambda=(412,443,488,531,555,667)$ & 2 & This study \\
$S_{\mathrm{CDM}}$ & 0.0185 & 2 & This study \\
$\eta$ & Eq. (A1) when class 2. & & Matsuoka et al. (2007) \\
& Otherwise 1.0 is applied. & 4 & (555)/0.2393 \\
\hline
\end{tabular}

Table A2. Regression analyses between $a_{\mathrm{CDOM}}(443)$ and $R_{\mathrm{rs}}(\lambda)$ band ratio using SBI spr and SBI sum datasets.

\begin{tabular}{lcc}
\hline Relationship & $r^{2}$ & $N$ \\
\hline$a_{\mathrm{CDOM}}(443)$ vs. $R_{\mathrm{rs}} 412 / R_{\mathrm{rs}} 555$ & 0.19 & 92 \\
$a_{\mathrm{CDOM}}(443)$ vs. $R_{\mathrm{rs}} 490 / R_{\mathrm{rs}} 555$ & 0.05 & 92 \\
$a_{\mathrm{CDOM}}(443)$ vs. $R_{\mathrm{rs}} 531 / R_{\mathrm{rs}} 555$ & 0.02 & 92 \\
\hline
\end{tabular}

\section{Appendix A}

In this study, we have a limited number of data for parameterizing $\eta$ and $S_{\mathrm{CDM}}$ as a function of $R_{\mathrm{rs}}(\lambda)$. These parameterizations were made using a large dataset including coastal waters from all over the world (Lee et al., 2009):

$\eta=2.0\left(1-1.2 \exp \left(-0.9 \frac{r_{\mathrm{rs}}(443)}{r_{\mathrm{rs}}(555)}\right)\right)$

and

$S_{\mathrm{CDM}}=0.015+\left(\frac{0.002}{0.6+\frac{r_{\mathrm{rs}}(443)}{r_{r s}(555)}}\right)$,

where $r_{\mathrm{rs}}(\lambda)$ represents below-surface $R_{\mathrm{rs}}(\lambda)$ as calculated by $R_{\mathrm{rs}}(\lambda) / 0.5238$ (Gordon et al., 1988). Consequently, we decided to apply these equations to our CDOM algorithm for coastal waters. Detailed performance of the algorithm using these is shown in Fig. 4 and Table 2.

The original code of the GSM algorithm (called GSM01) is now freely available on the ocean color website (http://oceancolor.gsfc.nasa.gov/DOCS/MSL12/master prodlist.html/\#prod15). To run our CDOM algorithm, this code needs to be modified (minor modification) using the specific relationships used in our study. These values are summarized in Table A1.
Acknowledgements. We are grateful to the captain and crews of the Canadian Icebreaker CCGS Amundsen, USCGC Healy, and Japanese R/V Mirai. Instrument development of C-OPS by J. H. Morrow is much appreciated. Datasets from SBI2002 cruises were provided by $\mathrm{V}$. Hill on the basis of the data policy (http://www.eol.ucar.edu/projects/sbi/). Sampling for these cruises was supported by the Arctic System Sciences program of the National Science Foundation OPP-0125049 and 0223375 and the National Aeronautics and Space Administration's (NASA) Sensor Intercomparison and Merger for Biological and Interdisciplinary Studies (SIMBIOS) program NAG5-10528. DOC concentrations during MALINA cruise were provided by R. Benner using funding from the US National Science Foundation (0713915). Comments by three anonymous reviewers, D. Christiansen-Stowe, and E. Boss have greatly helped in improving the manuscript. This study was conducted as part of the MALINA Scientific Program funded by ANR (Agence nationale de la recherche), INSU-CNRS (Institut national des sciences de l'univers - Centre national de la recherche scientifique), CNES (Centre national d'études spatiales) and ESA (European Space Agency).

Edited by: E. Boss

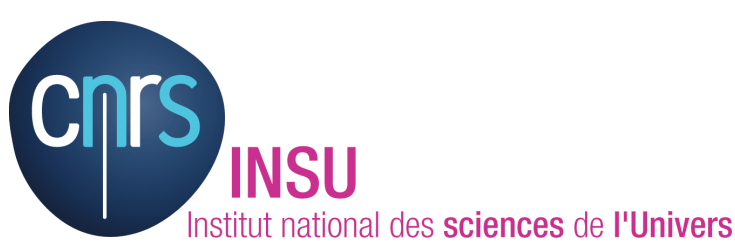

The publication of this article is financed by CNRS-INSU.

\section{References}

Andersen, S. B. and Knudsen, B. M.: The influence of vortex ozone depletion on Arctic ozone trends, Geophys. Res. Lett., 29, 2013, doi:10.1029/2001GL014595, 2002.

Babin, M., Stramski, D., Ferrari, G. M., Claustre, H., Bricaud, A., Obolensky, G., and Hoepffner, N.: Variations in the light absorption coefficients of phytoplankton, nonalgal particles, and dissolved organic matter in coastal waters around Europe, J. Geophys. Res., 108, 3211, doi:10.1029/2001JC000882, 2003. 
Bélanger, S., Xie, H., Krotkov, N., Larouche, P., Vincent, W. F., and Babin, M.: Photomineralization of terrigenous dissolved organic matter in Arctic coastal waters from 1979 to 2003: Interannual variability and implications of climate change, Global Biogeochem. Cy., 20, GB4005, doi:10.1029/2006GB002708, 2006.

Benner, R. and Strom, M.: A critical evaluation of the analytical blank associated with DOC measurements by high-temperature catalytic oxidation, Mar. Chem., 41, 153-160, 1993.

Bonilla, S., Rautio, M., and Vincent, W. F.: Phytoplankton and phytobenthos pigment strategies: implications for algal survival in the changing Arctic, Polar Biol., 32, 1293-1303, 2009.

Bricaud, A., Ciotti, A. M., and Gentili, B.: Spatial-temporal variations in phytoplankton size and colored detrital matter absorption at global and regional scales, as derived from twelve years of SeaWiFS data (1998-2009), Global Biogeochm. Cy., 26, GB1010, doi:10.1029/2010GB003952, 2012.

Calinski, T. and Harabasz, J.: A dendrite method for cluster analysis, Commun. Stat., 3, 1-27, 1974.

Camill, P.: Permafrost thaw accelerates in boreal peatlands during late-20th century climate warming, Climatic Change, 68, 135152,2005

Carder, K. L., Steward, R. G., Harvey, G. H., and Ortner, P. B.: Marine humic and fulvic acids: Their effects on remote sensing of ocean chlorophyll, Limnol. Oceanogr., 34, 68-81, 1989.

Doxaran, D., Ehn, J., Bélanger, S., Matsuoka, A., Hooker, S., and Babin, M.: Optical characterisation of suspended particles in the Mackenzie River plume (Canadian Arctic Ocean) and implications for ocean colour remote sensing, Biogeosciences, 9, 32133229, doi:10.5194/bg-9-3213-2012, 2012.

D'Sa, E. J.: Colored dissolved organic matter in coastal waters influenced by the Atchafalaya river, J. Appl. Remote Sens., 2, 023502, doi:10.1117/1.2838253, 2008.

Fichot, C. G. and Benner, R.: A novel method to estimate DOC cocentrations from CDOM absorption coefficients in coastal waters, Geophy. Res. Lett., 38, L03610, doi:10.1029/2010GL046152, 2011.

Fischer, G. and Karakas,, G.: Sinking rates and ballast composition of particles in the Atlantic Ocean: implications for the organic carbon fluxes to the deep ocean, Biogeosciences, 6, 85102, doi:10.5194/bg-6-85-2009, 2009.

Freeman, C., Evans, C. D., Monteith, D. T., Reynolds, B., and Fenner, N.: Export of organic carbon from peat soils, Nature, 412, p. 785, 2001

Frey, K. E. and Smith, L. C.: Amplified carbon release from vast West Siberian peatlands by 2100, Geophys. Res. Lett., 32, L09401, doi:10.1029/2004GL022025, 2005.

Garver, S. A. and Siegel, D. A.: Inherent optical property inversion of ocean color spectra and its biogeochemical interpretation, Time series from the Sargasso Sea, J. Geophys. Res., 102, 18607-18625, 1997.

Gordon, H. R.: Atmospheric correction of ocean color imagery in the Earth Observing System era, J. Geophys. Res., 102, 1708117106, 1997.

Gordon, H. R. and Wang, M.: Retrieval of water-leaving radiance and aerosol optical thickness over the oceans with SeaWiFS: a preliminary algorithm, Appl. Opt., 33, 443-452, 1994.

Gordon, H. R., Brown, O. B., Evans, R. H., Brown, J. W., Smith, R. C., Baker, K. S., and Clark, D. K.: A semianalytical radiance model of ocean color, J. Geophys. Res., 93, 10909-10924, 1988.
Hessen, D. O., Frigstad, H. Farovig, P. J., Wojewodzic, M. W., and Leu, E.: UV radiation and its effects on P-uptake in arctic diatoms, J. Exp. Mar. Biol. Ecol., 411, 45-51, 2012.

Hill, V.: Impacts of chromophoric dissolved organic material on surface ocean heating in the Chukchi Sea, J. Geophys. Res., 113, doi:10.1029/2007JC004119, 2008.

Holm-Hansen, O., Lorenzen, C. J., Holms, R. W., and Strickland, J. D. H.: Fluorometric Determination of Chlorophyll, J. Cons. Int. Explor. Mer., 30, 3-15, 1965.

Holmes, R. M., McClelland, J. W., Raymond, P. A., Franzer, B. B., Peterson, B. J., and Stieglitz, M.: Lability of DOC transported by Alaskan rivers to the Arctic Ocean, Geophys. Res. Lett., 35, L03402, doi:10.1029/2007GL032837, 2008.

Hooker, S. B., Morrow J. H., and Matsuoka A.: The $1 \%$ and $1 \mathrm{~cm}$ perspective in validationg and deriving AOP data products, Biogeosciences, in preparation, 2013.

International Ocean-Colour Coodinating Group: Remote sensing of inherent optical properties: fundamentals, tests, of algorithms and applications, in: Reports of the International Ocean-Colour Coordinating Group, No. 5, edited by: Lee, Z.-P., Dartmouth, NS, 126 pp., 2006.

Judd, K. E., Crump, B. C., and Kling, G. W.: Bacterial responses in activity and community composition to photo-oxidation of dissolved organic matter from soil and surface waters, Aquat. Sci., 69, 96-107, 2007.

Kishino, M., Takahashi M., Okami, N., and Ishimaru S.: Estimation of the Spectral Absorption Coefficients of Phytoplankton the sea, Bull. Mar. Sci., 37, 634-642, 1985.

Kostadinov, T. S., Siegel, D. A., Maritorena, S., and Guillpcheau, N.: Ocean color observations and modeling for an optically complex site: Santa Barbara Channel, California, USA, J. Geophys. Res., 112, C07011, doi:10.1029/2006JC003526, 2007.

Lee, Z. P., Carder, K. L., and Arnone, R. A.: Deriving inherent optical properties from water color: a multiband quasi-analytical algoritm for optically deep waters, Appl. Opt., 41, 5755-5772, 2002.

Lee, Z. P., Lubac, B., Werdell, J., and Arnone, R.: An update of the quasi-analytical algorithm (QAA-v5), open file online at: http://www.ioccg.org/groups/Software_OCA/QAA_v5.pdf, 9 pp., 2009.

Leu, E., Falk-Petersen, S., and Hessen, D. O.: Ultraviolet radiation negatively affects growth but not food quality of arctic diatoms, Limnol. Oceanogr., 52, 787-797, 2007.

Magnuson, A., Harding Jr., L. W., Mallonee, M. E., and Adolf, J. E.: Bio-optical model for Chesapeake Bay and the Middle Atlantic Bight, Estuar. Coast. Shelf Sci., 61, 403-424, 2004.

Mannino, A., Russ, M. E., and Hooker, S. B.: Algorithm development and validation for satellite-derived distributions of DOC and CDOM in the U.S. Middle Atlantic Bight, J. Geophys. Res., 113, C07051, doi:10.1029/2007JC004493, 2008.

Maritorena, S., Siegel, D. A., and Peterson, A. R.: Optimization of a semianalytical ocean color model for global-scale applications, Appl. Optics, 41, 2705-2714, 2002.

Matsuoka, A., Huot, Y., Shimada, K., Saitoh, S., and Babin, M.: Bio-optical characteristics of the Western Arctic Ocean: Implications for ocean color algorithms, Can. J. Remote Sen., 33, 503518, 2007.

Matsuoka, A., Larouche, P., Poulin, M., Vincent, W., and Hattori, H.: Phytoplankton community adaptation to changing light levels 
in the southern Beaufort Sea, Canadian Arctic, Estuar. Coast. Shelf Sci., 82, 537-546, 2009.

Matsuoka, A., Hill, V., Huot, Y., Bricaud, A., and Babin, M.: Seasonal variability in the light absorption properties of western Arctic waters: parameterization of the individual components of absorption for ocean color applications, J. Geophys. Res., 116, C02007, doi:10.1029/2009JC005594, 2011.

Matsuoka, A., Bricaud, A., Benner, R., Para, J., Sempéré, R., Prieur, L., Bélanger, S., and Babin, M.: Tracing the transport of colored dissolved organic matter in water masses of the Southern Beaufort Sea: relationship with hydrographic characteristics, Biogeosciences, 9, 925-940, doi:10.5194/bg-9-925-2012, 2012.

McClleland, J. W., Dery, S. J., Peterson, B. J., Holmes, R. M., and Wood, E. F.: A pan-arctic evaluation of changes in river discharge during the latter half of the 20th century, Geophys. Res. Lett., 33, L06715, doi:10.1029/2006GL025753, 2006.

Miller, W. L. and Moran, M. A.: Interaction of photochemical and microbial processes in the degradation of refractory dissolved organic matter from a coastal marine environment, Limnol. Oceanogr., 42, 1317-1324, 1997.

Miller, W. L., Moran, M. A., Sheldon, W. M., Zepp, R. G., and Opsahl, S.: Determination of apparent quantum yield spectra for the formation of biologically labile photoproducts, Limnol. Oceanogr., 47, 343-352, 2002.

Mitchell, B. G., Kahru M., Wieland J., and Stramska M.: Determination of spectral absorption coefficients of particles, dissolved materials and phytoplankton for discrete water samples, in: Ocean Optics Protocols For Satellite Ocean Color Sensor Validation, Revision 4, Volume 9, Inherent optical properties: instruments, characterization, field measurements and data analysis protocols, edited by: Mueller, J. L., Fargion, G. S., and McClain, C. R., NASA Tech. Rep., Greenbelt, Maryland, 39-64, 2003.

Morrow, J. H., Hooker, S. B., Booth, C. R., Bernhard, G., Lind, R. N., and Brown, J. W.: Advances in Measuring the Apparent Optical Properties (AOPs) of Optically Complex Waters, NASA Tech. Memo., 2010-215856, NASA Goddard Space Flight Center, Greenbelt, Maryland, 42-50, 2010.
Nelson, N. B. and Siegel, D. A.: Chromophoric DOM in the Open Ocean, in: Biogeochemistry of marine dissolved organic matter, edited by: Hansell, D. A. and Carlson, C. A., Academic press, San Diego, 2002.

Nelson, N. B., Siegel, D. A., and Michaels, A. F.: Seasonal dynamics of colored dissolved material in the Sargasso Sea, Deep Sea Res. Pt. 1, 45, 931-957, 1998.

Peterson, B. J., R, Holmes, M., McClelland, J. W., Vorosmarty, C. J., Lammers, R. B., Shiklomanov, A. I., Shiklomanov, I. A., and Rahmstorf, S.: Increasing river discharge to the Arctic Ocean, Science, 298, 2171-2173, 2002.

Siegel, D. A., Maritorena, S., Nelson, N. B., Hansell, D. A., and Lorenzi-Kayser, M.: Global distribution and dynamics of colored dissolved and detrital organic materials, J. Geophys. Res., 107, 3228, doi:10.1029/2001JC000965, 2002.

Suzuki, R. and Ishimaru, T.: An improved method for the determination of phytoplankton chlorophyll using n,ndimethylformamide, J. Oceanogr., 46, 190-194, 1990.

Wang, M. and Shi, W.: The NIR-SWIR combined atmospheric correction approach for MODIS ocean color data processing, Opt. Express, 15, 15722-15733, 2007.

Werdell, P. J. and Bailey, S. W.: An improved in-situ bio-optical data set for ocean color algorithm development and satellite data product validation, Remote Sens. Environ., 98, 122-140, 2005.

Wirth, M. and Renger, W.: Evidence of large scale ozone depletion within the arctic polar vortex 94/95 based on airborne LIDAR measurements, Geophys. Res. Lett., 23, 813-816, 1996.

Zhu, W., Yu, Q., Tian, Y. Q., Chen, R. F., and Gardner, G. B.: Estimation of chromophoric dissolved organic matter in the Mississippi and Atchafalaya river plume regions using above surface hyperspectral remote sensing, J. Geophys. Res., 116, C02011, doi:10.1029/2010JC006523, 2011. 